\title{
Optimization of Enhanced Geothermal System Power Generation Investment Scheme Based on Fuzzy VIKOR Model
}

\author{
Yan $\mathrm{Bu}^{1}$, Mingjing Guo ${ }^{1}$, Penghong Cheng ${ }^{2}$ \\ ${ }^{1}$ School of Economics and Management, China University of Geosciences (Wuhan), China \\ ${ }^{2}$ School of Management, Huazhong University of Science and Technology, China
}

\begin{abstract}
In the future, Enhanced Geothermal System (EGS) power generation will be a hot spot for new energy investment development. How to optimize the EGS power generation investment program is an important issue to be solved by the government and enterprises. In order to improve the accuracy of the EGS investment project evaluation, this paper proposes a technical route to optimize the EGS power generation investment program. It comprehensively considers the ambiguity of the decision attributes and the conflict between the indicators. The index is calculated using the entropy method and the order relationship method. Comprehensive weights; using triangular fuzzy numbers instead of exact numbers to reduce the loss of decision information; using a multi-criteria compromised sorting method to obtain trade-off solutions to solve the problem that investment plans cannot be accepted by all decision makers when there are multiple conflicting indicators. Finally, taking an enterprise's EGS power generation project as an example, the effectiveness and rationality of the optimized technology route for the EGS power generation investment program are verified.
\end{abstract}

\section{Introduction}

EGS (Enhanced Geothermal System), including the initial concept of Hot Dry Rock (HDR), was originated at the Los Alamos National Laboratory (LANL) in the USA [1]. The patent on the concept, which dates from 1974, describes the formation of an entirely natural tank designed for obtaining geothermal energy. In more than 40 years of research and development of the EGS, the utilization technology has matured day by day. The development prospect is very promising because of its great value. The potential of EGS resources in China is huge and the prospect of development is wide, which is higher than that estimated by the US(57 trillion tons of standard coal).Preliminary estimates indicate that EGS resources in the $3-10 \mathrm{~km}$ range are equivalent to 860 trillion tons of standard coal, of which 2 percent is equivalent to 4,040 times China's total energy consumption in 2010 [2-3].In particular, at $3.5-7.5 \mathrm{~km}$, the temperature of the EGS resources ranged from $150-250{ }^{\circ} \mathrm{C}$, and the amount of resources was huge, equivalent to 215 trillion tons of standard coal. In recent years, China has raised its green development strategy to an unprecedented level. The exploitation and utilization of geothermal resources are faced with historic development opportunities and great potential. EGS, as the clean energy with the most application value and potential for use, will play a more important role in optimizing energy structure, preventing and controlling atmospheric pollution, improving people's lives, and promoting the scientific and coordinated development of the economic and social ecological environment [4].

From the perspective of power construction costs, geothermal power generation is roughly 10,000 RMB installed $1 \mathrm{KW}$, which is equivalent to the cost of wind power generation, but compared with solar photovoltaic power generation of about 100,000 RMB installed 1KW, the construction cost is much lower [5]. From the viewpoint of environmental protection value, the utilization ratio of EGS resources can reach $80 \%$. Calculated according to the recoverable amount of $2 \%$ of China's EGS resources, it can replace the standard coal of 14.298 trillion tons, reducing $\mathrm{CO}_{2}$ emissions by 0.2388 trillion RMB, reduce the emission of $\mathrm{NO}_{\mathrm{x}}$ by 0.08579 trillion tons, reduce the emission of suspended dust by 0.1144 trillion tons, and reduce the coal ash residue by 1.4298 trillion tons [6]. From the perspective of natural conditions, the development and utilization of wind power, solar energy and tidal energy are all closely related to the climatic conditions, which often results in the instability and discontinuity of development and utilization. The development and utilization of geothermal energy do not have such problems.

For a long time in the future, as a significantly effective way of electricity generation, EGS will be a hot spot for new energy investment and development. In the face of a variety of EGS power generation investment plans, more comprehensive and reasonable decision-making system are needed. The optimization of EGS power generation investment plan is a multi-criteria decision-making problem. The decision-making process 
needs to consider many factors such as resources, economy, environment and risk. The traditional multi-criteria decision-making problems mainly include analytic hierarchy process (AHP), analytic network process (ANP) and technique for order preference by similarity to ideal solution (TOPSIS). However, there are some problems in the application of existing multi-criteria decision-making methods to the selection of EGS power generation projects, which will reduce the accuracy of decision-making. On the one hand, due to the fact that the EGS power generation industry is still commercialized in China, there are few data available for reference in the investment decision-making process, and it is difficult to obtain the precise data needed for general methods. On the other hand, due to the complexity of decision-making issues and the conflict between the indicators of the EGS power generation project, the evaluation results may not be accepted by all policy makers. Based on the above problems, this paper proposes a preferred framework for the EGS power generation investment plan based on fuzzy set theory [7-8] and multi-criteria compromised sorting method [9-11].The use of triangular fuzzy numbers to represent the decision values of each candidate item prevents the loss of decision information. Through the multi-criteria compromised sorting method, ranking of a series of solutions with multiple conflicts or inconsistent indicators can be achieved, so as to better complete the optimization of the investment scheme of the EGS power generation.

\section{EGS power generation investment program evaluation index system}

The construction of investment evaluation index system is the basic work for optimizing the investment project, and whether the index system is properly constructed will directly affect the accuracy of the project selection. EGS power generation project includes many aspects, especially when it is a government investment project, it needs to consider social and environmental factors. This paper will build 25 indicators through the five criteria of strengths, quality, economy, risk, and environment to evaluate a power generation project in EGS, as shown in Table 1.

Table 1. Evaluation index system of EGS power generation investment plan.

\begin{tabular}{|c|c|c|}
\hline Guidelines & Primary indicators & Secondary indicators \\
\hline \multirow{5}{*}{ (A) Advantage } & \multirow{2}{*}{ (a) Resources } & $\left(a_{1}\right)$ Exploitable resources \\
\hline & & $\left(a_{2}\right)$ EGS temperature \\
\hline & \multirow{3}{*}{ (b) Location } & $\left(b_{1}\right)$ Geological terrain conditions \\
\hline & & $\left(b_{2}\right)$ Mining depth \\
\hline & & $\left(b_{3}\right)$ Grid conditions \\
\hline \multirow{6}{*}{ (B) Quality } & \multirow{4}{*}{ (c) EGS system } & $\left(c_{1}\right)$ Annual installed capacity \\
\hline & & $\left(c_{2}\right)$ Technical maturity \\
\hline & & $\left(c_{3}\right)$ Adaptability to local resources \\
\hline & & $\left(c_{4}\right)$ Resistance to geological disasters \\
\hline & \multirow{2}{*}{ (d) Construction } & $\left(d_{1}\right)$ Construction plan \\
\hline & & $\left(d_{2}\right)$ Construction management level \\
\hline \multirow{6}{*}{ (C) Economic } & \multirow{3}{*}{ (e) Investment } & $\left(e_{1}\right)$ Fixed asset investment \\
\hline & & $\left(e_{2}\right)$ Liquidity investment \\
\hline & & $\left(e_{3}\right)$ Annual operating costs \\
\hline & \multirow{3}{*}{ ( $f$ ) Benefit } & $\left(f_{1}\right)$ Internal Rate of Return(\%) \\
\hline & & $\left(f_{2}\right)$ Payback period (a) \\
\hline & & $\left(f_{3}\right)$ Policy subsidies \\
\hline \multirow{4}{*}{ (D) Risk } & \multirow{2}{*}{ (g) Social risk } & $\left(g_{1}\right)$ Policy change risk \\
\hline & & $\left(g_{2}\right)$ Project start-up operational risk \\
\hline & \multirow{2}{*}{ (h) Technical risk } & $\left(h_{1}\right)$ Construction technology risk \\
\hline & & $\left(h_{2}\right)$ Equipment installation technology risk \\
\hline \multirow{5}{*}{ (E) Environment } & \multirow{2}{*}{ (i) Positive effect } & $\left(i_{1}\right)$ Pollutant emission reduction \\
\hline & & $\left(i_{2}\right)$ Energy saving effect \\
\hline & \multirow{3}{*}{ (j) Negative effect } & $\left(j_{1}\right)$ Sound pollution \\
\hline & & $\left(j_{2}\right)$ Air Pollution \\
\hline & & $\left(j_{3}\right)$ Water pollution \\
\hline
\end{tabular}




\section{EGS power generation investment program optimization technical route}

The technical route for the investment program optimization is based on the investment decision-making process of the EGS power generation project. The entire technical route is divided into three parts: The determination of alternatives for evaluation, the establishment of indicator systems, the determination of weights, and the determination of optimal plans for investment plans. The specific technical route is shown in Fig. 1. Through the cooperation of these three parts, the scientific sequencing of alternatives can finally be achieved, assisting the investment decision of the hot rock power generation investment company.

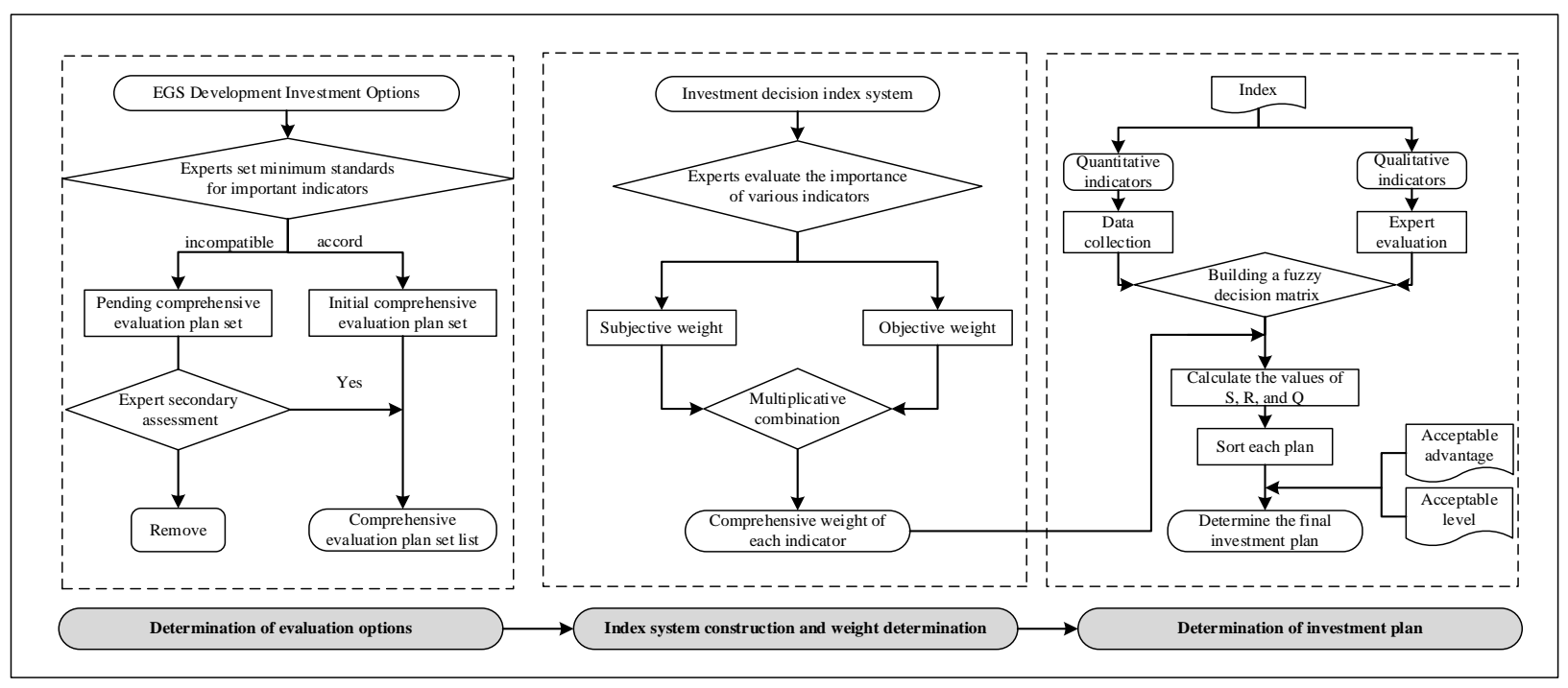

Fig. 1. EGS Power Generation Investment Optimization Technology Roadmap.

\subsection{Determination of evaluation options}

This article first screens the investment alternatives, and through the relevant screening process, removes some of the investment options from the investment alternatives that do not meet the requirements. The retained investment plans form an evaluation alternative set and enter the subsequent comprehensive evaluation link.

In the first step, the company invited experts from the EGS power generation field to form an expert committee to take charge of this assessment. In the second step, according to the opinions of the enterprise's decision makers and the project feasibility study report, the experts set the minimum standards for some important indicators (in the case of cost indicators, they are the maximum standards). If the value of the relevant indicator is higher than the minimum standard (the cost type indicator is below), the investment plan goes directly to the evaluation candidate set. The third step provides a second opportunity for investment plans that fail to enter the alternative set. Experts analyze the investment value of the project based on the feasibility study report and explore the investment potential of the project. If part of the investment indicators of the project are attractive, they are also allowed to enter the set of evaluation options after consensus of the experts. The fourth step, through these two rounds of assessment, forms a list of options for evaluation. Comprehensive evaluation of the investment plan on the list, select the most appropriate investment plan.

\subsection{Determination of index weights based on comprehensive integrated weighting method}

Due to the large number of indicators and the weak correlation, this paper intends to adopt a comprehensive integrated weighting method that considers the objective conditions of each item's indicators and also includes the subjective opinions of experts on the importance of each index. The objective weights were determined by the method of entropy weight, and the subjective weights of each index were determined by using the group-based order relation method.

\subsubsection{Objective weight calculation}

The entropy weight method [12] is a method for determining the weight of an evaluation object based on the amount of information provided by the evaluation index observation value. In the comprehensive evaluation, this paper uses information entropy to obtain the degree of systematic information and evaluates the utility value of information.

According to the entropy method to determine the weight coefficient steps are as follows:

Step 1: Perform dimensionless operations on the attribute values of the $\mathrm{j}$-th index of i-project 


$$
P_{i j}=\frac{x_{i j}}{\sum_{i=1}^{n} x_{i j}}
$$

Step 2: Calculate the entropy of the $\mathrm{j}$-th indicator

$$
E\left(x_{j}\right)=-(\ln n)^{-1} \sum_{i=1}^{m} P_{i j} \ln P_{i j}
$$

Step 3: Calculate the objective weight of the $j$-th indicator

When $P_{i j}=0$, then $E\left(x_{j}\right)=0$, we can see $0 \leq E\left(x_{j}\right) \leq 1$, , the degree of deviation of the $\mathrm{j}$ index attribute under each scheme $d_{j}=1-E\left(x_{j}\right)$, the objective weight of the j-th index

$$
w_{j}^{0}=\frac{d_{j}}{\sum_{j=1}^{m} d_{j}} \quad(j=1,2, \cdots, m)
$$

According to the entropy weight calculation formula above, the objective weights of the evaluation indexes of m EGS power generation investment plans are obtained.

\subsubsection{Subjective weight calculation}

Step 1: determine the order relationship

Each expert individually selects the most important index for the investment decision of EGS power generation projects from the index set $\left\{X_{1}, X_{2}, \cdots, X_{m}\right\}$, marked as $X_{1}^{*}$, and then picks out the most important indicators from among the unselected indicators. Until all the indicators have been selected, this forms an index of importance: $X_{1}^{*}>X_{2}^{*}>\cdots>X_{m}^{*}$.

Step 2: Determination of the ratio of the importance of each index

The ratio of the importance of the evaluation indicators $X_{j-1}$ and $X_{j}$ to the expert is denoted as $r_{k}$ [13]. The table for the assignment of $r_{k}$ is shown in Table 2:

$\frac{w_{j-1}}{w_{j}}=r_{j}, k=m, m-1, m-2, \ldots, 3,2$

Table 2. $\boldsymbol{r}_{\boldsymbol{j}}$ assignment table.

\begin{tabular}{|c|c|}
\hline $\boldsymbol{r}_{\boldsymbol{j}}$ & Instructions \\
\hline 1.0 & $\begin{array}{l}\text { The evaluation index } X_{k-1} \text { has the same degree of importance } \\
\text { as } X_{k}\end{array}$ \\
\hline 1.2 & The evaluation index $X_{k-1}$ is slightly more important than $X_{k}$ \\
\hline 1.4 & The evaluation index $X_{k-1}$ is significantly more important than \\
& The evaluation index $X_{k-1}$ is more important than $X_{k}$ \\
\hline 1.6 & Evaluation index $X_{k-1}$ is more important than $X_{k}$ \\
\hline 1.8 &
\end{tabular}

Step 3: Calculation of Group Order Weights

If all experts form a consistent order relationship, the weight calculation formula is

$$
\left\{\begin{array}{l}
w_{m}^{*}=\left(1+\sum_{k=2}^{m} \prod_{i=k}^{m} r_{i}^{*}\right)^{-1} \\
w_{j-1}^{*}=r_{j}^{*} w_{j}^{*}, \quad j=m, \cdots, 2 \\
r_{j}^{*}=\frac{1}{L} \sum_{k=1}^{L} r_{k j}, j=2, \cdots, m
\end{array}\right.
$$

Where: $L$ represents the number of experts; $r_{k j}$ represents the ratio of expert $k$ to the importance of the indicator $X_{j-1}^{*}$ and $X_{j}^{*} ; w_{j}^{*}$ represents the weight of indicator $\mathrm{j}$. If the ordering relationship formed by experts is inconsistent, assuming the h-order relationship is formed, the weight under each order relationship is calculated according to formula (5), and the final comprehensive weight is obtained through the weighted average method.

$$
w_{j}^{1}=\sum_{s=1}^{h} k_{s} w_{j s}
$$

In the formula: $w_{j s}$ represents the weights under $s$ sorting; $k_{s}$ represents the number of experts forming the s-th sort.

\subsubsection{Comprehensive weight calculation}

The objective weights $w_{j}^{0}$ and subjective weights $w_{j}^{1}$ are combined by multiplication, and the adjusted comprehensive weights are as follows:

$$
\widetilde{w}_{j}=\frac{w_{j}^{1} \times w_{j}^{0}}{\sum_{j=1}^{m} w_{j}^{1} \times w_{j}^{0}}
$$

\subsection{Optimization based on fuzzy VIKOR investment plan}

Suppose an EGS power generation project investment multi-criteria problem with $\mathrm{K}$ decision makers $L_{k}(k=1,2, \cdots, K), n$ alternatives $P_{i}(i=1,2, \cdots, n)$ and $m$ decision indicators $C_{j}(j=1,2, \cdots, m)$.

\subsubsection{Initial fuzzy decision matrix}

Let the initial fuzzy decision matrix be $\mathrm{X}=\left(\tilde{X}_{i j}\right)_{n \times m}$, which consists of two parts: the quantitative index decision value and the qualitative index decision value.

Table 3. Linguistic ratings and fuzzy numbers.

\begin{tabular}{|c|c|c|}
\hline $\begin{array}{c}\text { Linguistic Term } \\
\text { (criteria) }\end{array}$ & $\begin{array}{c}\text { Linguistic Term } \\
\text { (alternative) }\end{array}$ & $\begin{array}{c}\text { Fuzzy Triangular } \\
\text { Number }\end{array}$ \\
\hline Very Low & Very poor (VP) & $(1,1,3)$ \\
\hline Low & Poor (P) & $(1,3,5)$ \\
\hline Medium & Fair (F) & $(3,5,7)$ \\
\hline High & Good (G) & $(5,7,9)$ \\
\hline Very High & Very Good (VG) & $(7,9,9)$ \\
\hline
\end{tabular}

Qualitative indicators are obtained through expert scoring. Experts use linguistic variables to score the qualitative indicators of alternatives. Then based on the relationship in Table 3, the scoring results will be converted into triangular fuzzy numbers. Suppose that the triangular fuzzy number $\tilde{X}_{i j}^{k}=$ $\left(x_{i j 1}^{k}, x_{i j 2}^{k}, x_{i j 3}^{k}\right)$ represents the decision value of the kth expert on the $j$ th qualitative indicator of the $i$ th equipment scheme, and $\lambda_{k}$ represents the k-th expert decision weight $\tilde{X}_{i j}=\left(x_{i j 1}, x_{i j 2}, x_{i j 3}\right)$ represents the index decision value of multiple experts.

$$
\left\{\begin{array}{l}
x_{i j 1}=\sum_{k=1}^{k} \lambda_{k} x_{i j 1}^{k} \\
x_{i j 2}=\sum_{k=1}^{k} \lambda_{k} x_{i j 2}^{k} \\
x_{i j 3}=\sum_{k=1}^{k} \lambda_{k} x_{i j 3}^{k}
\end{array}\right.
$$

For quantitative indicators, the real data is converted to triangular fuzzy numbers through fuzzification. Conversion method is 


$$
\left\{\begin{array}{c}
x_{i j 1}=d_{i j}\left(1-\alpha_{j}\right) \\
x_{i j 2}=d_{i j} \\
x_{i j 3}=d_{i j}\left(1+\beta_{j}\right)
\end{array}\right.
$$

In the formula: $d_{i j}$ represents the real value of the $\mathrm{j}$-th quantitative index of the $\mathrm{i}$-th alternative; $\alpha$ and $\beta$ represent the fluctuation coefficient of the data downwards and upwards in an uncertain environment, whose value is determined by the expert.

\subsubsection{Initial fuzzy matrix standardization}

Since the original quantitative index values have different dimensions, they cannot be directly compared and standardization is required before evaluation. After the normalized matrix is $A=\left(\tilde{A}_{i j}\right)_{n \times m}$, the standardized method is

$$
\tilde{A}_{i j}=\left\{\begin{array}{lr}
\left(\frac{x_{i j 1}}{x_{j 1}^{+}}, \frac{x_{i j 2}}{x_{j 3}^{+}}, \frac{x_{i j 3}}{x_{j 3}^{+}}, r\right. & c_{i} \in \Omega_{b} \\
\left(\frac{x_{j 1}^{-}}{x_{i j 3}}, \frac{x_{j 1}^{-}}{x_{i j}}, \frac{x_{j 1}^{-}}{x_{i j 1}}\right), & c_{i} \in \Omega_{c}, x_{j 1}^{-} \neq 0 \\
\left(1-\frac{x_{i j 3}}{x_{j 3}^{+}}, 1-\frac{x_{i j 2}}{x_{j 3}^{+}}, 1-\frac{x_{i j 1}}{x_{j 3}^{+}}\right), & c_{i} \in \Omega_{c}, x_{j 1}^{-}=0
\end{array}\right.
$$

Where: $\quad x_{j 3}^{+}=\max _{i}\left\{x_{i j 3}\right\} \quad ; \quad x_{j 1}^{-}=\min _{i}\left\{x_{i j 1}\right\}$; $\Omega_{b}$ represents a profitable index; $\Omega_{c}$ represents a cost index.

\subsubsection{Ordering and optimization of investment programs}

The purpose of this section is to sort the alternatives by a fuzzy multi-criteria compromise solution ranking method and make decisions according to the corresponding regulations.

Step1: determine the positive and negative fuzzy ideal solution of each index

Positive fuzzy ideal solution

$$
\widetilde{F}_{j}^{+}=\left(a_{j 1}^{+}, a_{j 2}^{+}, a_{j 3}^{+}\right)
$$

In the formula: $a_{j 1}^{+}=\max _{i}\left\{a_{i j 1}\right\} ; a_{j 2}^{+}=\max _{i}\left\{a_{i j 2}\right\}$; $a_{j 3}^{+}=\max _{i}\left\{a_{i j 3}\right\}$.

Negative fuzzy ideal solution

$$
\tilde{F}_{j}^{-}=\left(a_{j 1}^{-}, a_{j 2}^{-}, a_{j 3}^{-}\right)
$$

In the formula: $a_{j 1}^{-}=\min _{i}\left\{a_{i j 1}\right\} ; a_{j 2}^{-}=\min _{i}\left\{a_{i j 2}\right\}$; $a_{j 3}^{-}=\min _{i}\left\{a_{i j 3}\right\}$.

Step 2: Calculate the fuzzy distance

The vertex method is used to determine the distance between two triangular fuzzy numbers.

$$
\begin{aligned}
& D\left(\tilde{F}_{j}^{+}, \widetilde{U}_{i j}\right)=\sqrt{\frac{1}{3}\left[\left(a_{j 1}^{+}-a_{i j 1}\right)^{2}+\left(a_{j 2}^{+}-a_{i j}\right)^{2}+\left(a_{j 3}^{+}-a_{i j 3}\right)^{2}\right]} \quad(13) \\
& D\left(\tilde{F}_{j}^{+}, \tilde{F}_{j}^{-}\right)=\sqrt{\frac{1}{3}\left[\left(a_{j 1}^{+}-a_{j 1}^{-}\right)^{2}+\left(a_{j 2}^{+}-a_{j 2}^{-}\right)^{2}+\left(a_{j 3}^{+}-a_{j 3}^{-}\right)^{2}\right]}(14)
\end{aligned}
$$

Step 3: Calculate group effect value $S_{i}$ and individual regret value $R_{i}$

$$
\begin{gathered}
S_{i}=\sum_{j=1}^{m} w_{j} D\left(\tilde{F}_{j}^{+}, \widetilde{U}_{i j}\right) / D\left(\tilde{F}_{j}^{+}, \tilde{F}_{j}^{-}\right) \\
R_{i}=\max _{i}\left[D\left(\widetilde{F}_{j}^{+}, \widetilde{U}_{i j}\right) / D\left(\tilde{F}_{j}^{+}, \tilde{F}_{j}^{-}\right)\right]
\end{gathered}
$$

Step 4: Calculate the comprehensive index value of multiple criteria and multiple compromises

$$
S^{+}=\min _{i}\left\{S_{i}\right\} \quad S^{-}=\max _{i}\left\{S_{i}\right\}
$$

$$
\begin{gathered}
R^{+}=\min _{i}\left\{R_{i}\right\}, R^{-}=\max _{i}\left\{R_{i}\right\} \\
Q_{i}=v \frac{S_{i}-S^{+}}{S^{-}-S^{+}}+(1-v) \frac{R_{i}-R^{+}}{R^{-}-R^{+}}
\end{gathered}
$$

Where $v$ denotes the coefficient of the decision mechanism, $v>0.5$ denotes the decision based on the group effect, $\mathrm{v}>0.5$ denotes the decision based on the individual regret criterion, $\mathrm{v}=0.5$ denotes that the group effect and individual regrets are taken into account simultaneously to make the decision [9-11].

Step 5: Determine the compromise

According to the ascending ordering of $S_{i}, R_{i}$, and $Q_{i}$ values for each device scheme, let $B^{1}$ and $B^{2}$ be the top 2 rankings after sorting by $Q_{i}$ values. If $B^{1}$ satisfies the following two conditions, it is a trade-off solution.

Condition 1: Acceptable advantages

$$
\mathrm{Q}\left(B^{2}\right)-\mathrm{Q}\left(B^{1}\right) \geq 1 /(n-1)
$$

Where $n$ is the number of evaluation alternatives.

Condition 2: Acceptable stability in the decision-making process

$B^{1}$ must also be ranked first in the order of $S_{i}, R_{i}$. If there is a condition that cannot be satisfied, a series of tradeoffs will be generated, including the following two conditions:

Case I: If only condition 2 cannot be met, $B^{1}$ and $B^{2}$ are tradeoff solutions;

Case 2: If the condition is not satisfied, $B^{1}, B^{2}, \ldots$, $B^{N}$ are all trade-off solutions, and $B^{N}$ is satisfied by the relation $Q\left(B^{N}\right)-Q\left(B^{1}\right)<1 /(n-1)$ The maximum $N$ value is determined.

\section{Example analysis}

A new energy investment company plans to invest in the EGS power station project in northwestern China. Through the previous research, a number of potential investment plans have been formed. The following multi-criteria decision-making is used to select the EGS power generation investment with high value.

\subsection{Determination of evaluation options}

According to the company's strategy and regional hot rock development and utilization policy, the company has identified five potential investment plans, labeled $T_{1}$, $T_{2}, T_{3}, T_{4}$ and $T_{5}$. The company invited five experts in the field of investment in the hot rock power generation project to optimize this plan. After the minimum standards and expert second evaluation, the final investment plans $T_{1}, T_{3}$ and $T_{4}$ carry out the subsequent comprehensive evaluation, renumbered as $\mathrm{D}_{1}, \mathrm{D}_{2}$ and $\mathrm{D}_{3}$, respectively.

\subsection{Calculation of indicator weights}

After the assessment of the options was finalized, the Committee of Experts began to calculate the index weights. First, the expert committee evaluates each of the three alternatives based on the project feasibility report, 
and calculates the objective weights based on the entropy method. Secondly, five experts ranked the importance of each index in the indicator system, forming a total of 1 order relations, 2 order relations 2, and 2 order relations 3 , and calculated subjective weights based on the order relation method. Finally, the subjective weights and objective weights are calculated by the formula of the multiplicative combination and the comprehensive weights are calculated. The specific weights are shown in Table 4.

\subsection{Optimization of investment program}

\subsubsection{Obtaining and standardizing fuzzy decision data}

First, each secondary index is classified by nature and type. Indicators $a_{1}, a_{2}, b_{1}, c_{1}, e_{1}-e_{3}$, and $f_{1}-f_{3}$ are quantitative indicators, and others are qualitative indicators. In the same way, indicators $e_{1}-e_{3}, f_{1}, f_{2}, g_{1}, g_{2}$, $h_{1}, h_{2}, j_{1}-j_{3}$ are cost indicators, and others are profit-oriented indicators.

Second, due to the different nature of the secondary indicators, different methods are needed to obtain their fuzzy decision values. Experts $\left(S_{1}, S_{2}, S_{3}, S_{4}, S_{5}\right)$ use linguistic variables to score the qualitative indicators of each investment plan. Then the expert scoring results are converted into triangular fuzzy numbers according to Table 3, and the fuzzy decision value of each expert's qualitative indicator is obtained, as shown in Table 5. According to formula (8), each expert's decision value is summarized and the comprehensive decision value of the qualitative indicator is obtained.

After the determination of the qualitative indicator decision value is completed, the expert committee needs to negotiate the fluctuation coefficient of each quantitative indicator. The upward volatility coefficient indicates the magnitude of the growth of the decision value under uncertainty, and the downward fluctuation coefficient indicates the magnitude of the decline of the decision value. Obtain specific quantitative decision-making values from the project feasibility study report, and then convert the real data into triangular fuzzy numbers according to formula (9) to obtain quantitative fuzzy decision values. Finally, according to formula (10), the fuzzy decision data is standardized so that the decision values of each index are comparable. The standardized data is shown in Table 6.

Table 4. Determination of subjective and objective weights.

\begin{tabular}{|c|c|c|c|c|c|}
\hline Guidelines & First-level indicators & Secondary indicators & $w_{j}^{0}$ & $w_{j}^{1}$ & $\widetilde{w}_{j}$ \\
\hline \multirow{5}{*}{ Advantage (0.3212) } & \multirow{2}{*}{$\begin{array}{l}\text { Resources } \\
(0.2312)\end{array}$} & $a_{1}$ & 0.0802 & 0.0921 & 0.1443 \\
\hline & & $a_{2}$ & 0.0625 & 0.0712 & 0.0869 \\
\hline & \multirow{3}{*}{$\begin{array}{l}\text { Location } \\
(0.0900)\end{array}$} & $b_{1}$ & 0.0186 & 0.0164 & 0.0060 \\
\hline & & $b_{2}$ & 0.0132 & 0.0104 & 0.0027 \\
\hline & & $b_{3}$ & 0.0681 & 0.0612 & 0.0814 \\
\hline \multirow{6}{*}{$\begin{array}{l}\text { Quality } \\
(0.2898)\end{array}$} & \multirow{4}{*}{$\begin{array}{l}\text { EGS system } \\
(0.2716)\end{array}$} & $c_{1}$ & 0.0754 & 0.0715 & 0.1053 \\
\hline & & $c_{2}$ & 0.0528 & 0.0422 & 0.0435 \\
\hline & & $c_{3}$ & 0.0423 & 0.0315 & 0.0260 \\
\hline & & $c_{4}$ & 0.0603 & 0.0822 & 0.0968 \\
\hline & \multirow{2}{*}{$\begin{array}{l}\text { Construction } \\
(0.0182)\end{array}$} & $d_{1}$ & 0.0022 & 0.0087 & 0.0004 \\
\hline & & $d_{2}$ & 0.0286 & 0.0319 & 0.0178 \\
\hline \multirow{6}{*}{ Economic (0.2301) } & \multirow{3}{*}{$\begin{array}{c}\text { Investment } \\
(0.1111)\end{array}$} & $e_{1}$ & 0.0674 & 0.0717 & 0.0944 \\
\hline & & $e_{2}$ & 0.0321 & 0.0218 & 0.0137 \\
\hline & & $e_{3}$ & 0.0137 & 0.0115 & 0.0031 \\
\hline & \multirow{3}{*}{$\begin{array}{l}\text { Benefit } \\
(0.1189)\end{array}$} & $f_{1}$ & 0.0627 & 0.0705 & 0.0863 \\
\hline & & $f_{2}$ & 0.0372 & 0.0381 & 0.0277 \\
\hline & & $f_{3}$ & 0.0188 & 0.0134 & 0.0049 \\
\hline \multirow{4}{*}{$\begin{array}{c}\text { Risk } \\
(0.0649)\end{array}$} & \multirow{2}{*}{$\begin{array}{l}\text { Social risk } \\
(0.0487)\end{array}$} & $g_{1}$ & 0.0501 & 0.0429 & 0.0420 \\
\hline & & $g_{2}$ & 0.0211 & 0.0163 & 0.0067 \\
\hline & \multirow{2}{*}{$\begin{array}{l}\text { Technical risk } \\
\quad(0.0162)\end{array}$} & $h_{1}$ & 0.0259 & 0.0118 & 0.0060 \\
\hline & & $h_{2}$ & 0.0177 & 0.0295 & 0.0102 \\
\hline \multirow{3}{*}{$\begin{array}{l}\text { Environment } \\
(0.0940)\end{array}$} & \multirow{2}{*}{$\begin{array}{l}\text { Positive effect } \\
\quad(0.0298)\end{array}$} & $i_{1}$ & 0.0301 & 0.0289 & 0.0170 \\
\hline & & $i_{2}$ & 0.0225 & 0.0292 & 0.0128 \\
\hline & Negative effect & $j_{1}$ & 0.0288 & 0.0231 & 0.0130 \\
\hline
\end{tabular}




\begin{tabular}{|l|l|l|l|l|l|}
\hline \multirow{2}{*}{$(0.0642)$} & $j_{2}$ & 0.0259 & 0.0243 & 0.0123 \\
\cline { 3 - 5 } & & $j_{3}$ & 0.0418 & 0.0477 & 0.0389 \\
\hline
\end{tabular}

Table 5. Fuzzy decision values of qualitative indicators.

\begin{tabular}{|c|c|c|c|c|c|c|c|c|c|c|c|c|c|c|c|}
\hline \multirow{2}{*}{ Index } & \multicolumn{5}{|c|}{$D_{1}$} & \multicolumn{5}{|c|}{$D_{2}$} & \multicolumn{5}{|c|}{$D_{3}$} \\
\hline & $S_{1}$ & $S_{2}$ & $S_{3}$ & $S_{4}$ & $S_{5}$ & $S_{1}$ & $S_{2}$ & $S_{3}$ & $S_{4}$ & $S_{5}$ & $S_{1}$ & $S_{2}$ & $S_{3}$ & $S_{4}$ & $S_{5}$ \\
\hline$b_{1}$ & $\mathrm{M}$ & $\mathrm{M}$ & $\mathrm{H}$ & $\mathrm{M}$ & $\mathrm{H}$ & $\mathrm{M}$ & $\mathrm{L}$ & $\mathrm{M}$ & $\mathrm{H}$ & $\mathrm{M}$ & $\mathrm{H}$ & $\mathrm{L}$ & $\mathrm{H}$ & $\mathrm{M}$ & M \\
\hline$b_{3}$ & $\mathrm{~L}$ & $\mathrm{M}$ & $\mathrm{M}$ & $\mathrm{M}$ & $\mathrm{H}$ & $\mathrm{H}$ & $\mathrm{M}$ & $\mathrm{M}$ & $\mathrm{M}$ & $\mathrm{M}$ & $\mathrm{M}$ & $\mathrm{M}$ & $\mathrm{L}$ & $\mathrm{M}$ & $\mathrm{H}$ \\
\hline$c_{2}$ & $\mathrm{H}$ & $\mathrm{M}$ & $\mathrm{L}$ & $\mathrm{M}$ & $\mathrm{L}$ & L & $\mathrm{H}$ & $\mathrm{L}$ & $\mathrm{L}$ & M & $\mathrm{L}$ & $\mathrm{M}$ & $\mathrm{L}$ & $\mathrm{M}$ & $\mathrm{L}$ \\
\hline$c_{3}$ & $\mathrm{~L}$ & VL & VL & $\mathrm{L}$ & $\mathrm{M}$ & $\mathrm{L}$ & $\mathrm{L}$ & $\mathrm{M}$ & $\mathrm{M}$ & $\mathrm{L}$ & $\mathrm{M}$ & $\mathrm{L}$ & $\mathrm{M}$ & $\mathrm{L}$ & $\mathrm{L}$ \\
\hline$c_{4}$ & $\mathrm{H}$ & $\mathrm{VH}$ & $\mathrm{H}$ & $\mathrm{VH}$ & $M$ & $\mathrm{H}$ & $M$ & $\mathrm{H}$ & $\mathrm{VH}$ & $\mathrm{H}$ & $\mathrm{H}$ & $\mathrm{M}$ & $\mathrm{H}$ & $\mathrm{H}$ & $\mathrm{VH}$ \\
\hline$d_{1}$ & $\mathrm{VH}$ & $\mathrm{M}$ & $\mathrm{H}$ & $\mathrm{H}$ & $\mathrm{VH}$ & $\mathrm{M}$ & $\mathrm{H}$ & VH & $\mathrm{H}$ & $\mathrm{M}$ & $\mathrm{VH}$ & $\mathrm{H}$ & $\mathrm{H}$ & $\mathrm{H}$ & $\mathrm{M}$ \\
\hline$d_{2}$ & $\mathrm{H}$ & $\mathrm{L}$ & $\mathrm{H}$ & $\mathrm{M}$ & $\mathrm{H}$ & $\mathrm{H}$ & $\mathrm{H}$ & $\mathrm{M}$ & $\mathrm{H}$ & $\mathrm{H}$ & $\mathrm{H}$ & $\mathrm{H}$ & $\mathrm{M}$ & $\mathrm{M}$ & $\mathrm{H}$ \\
\hline$g_{1}$ & $\mathrm{H}$ & $\mathrm{H}$ & $\mathrm{M}$ & $\mathrm{H}$ & $\mathrm{L}$ & $\mathrm{L}$ & $\mathrm{H}$ & $\mathrm{H}$ & $\mathrm{H}$ & $\mathrm{M}$ & $\mathrm{H}$ & $\mathrm{H}$ & $\mathrm{L}$ & $\mathrm{H}$ & $\mathrm{VH}$ \\
\hline$g_{2}$ & $\mathrm{H}$ & $\mathrm{M}$ & $\mathrm{L}$ & $\mathrm{H}$ & M & $\mathrm{H}$ & $\mathrm{H}$ & $\mathrm{L}$ & $\mathrm{M}$ & $\mathrm{VH}$ & $\mathrm{VH}$ & $\mathrm{L}$ & M & $\mathrm{H}$ & $\mathrm{H}$ \\
\hline$h_{1}$ & M & $\mathrm{M}$ & $\mathrm{H}$ & $\mathrm{M}$ & $\mathrm{H}$ & $\mathrm{M}$ & $\mathrm{H}$ & $\mathrm{M}$ & $\mathrm{H}$ & $\mathrm{L}$ & $\mathrm{H}$ & $\mathrm{H}$ & $\mathrm{M}$ & $\mathrm{M}$ & M \\
\hline$h_{2}$ & $\mathrm{VH}$ & VH & $\mathrm{H}$ & VH & M & VH & VH & $\mathrm{H}$ & $\mathrm{H}$ & $\mathrm{H}$ & M & $\mathrm{M}$ & $\mathrm{H}$ & $\mathrm{H}$ & $\mathrm{VH}$ \\
\hline$i_{1}$ & $\mathrm{H}$ & $\mathrm{M}$ & $\mathrm{L}$ & $\mathrm{H}$ & $\mathrm{M}$ & $\mathrm{H}$ & $\mathrm{H}$ & $\mathrm{H}$ & $\mathrm{M}$ & $\mathrm{L}$ & $\mathrm{H}$ & $\mathrm{M}$ & VH & $\mathrm{L}$ & M \\
\hline$i_{2}$ & $\mathrm{VH}$ & VH & $\mathrm{H}$ & $\mathrm{M}$ & $\mathrm{H}$ & $\mathrm{H}$ & $\mathrm{M}$ & VH & $\mathrm{H}$ & $\mathrm{H}$ & $\mathrm{VH}$ & $\mathrm{H}$ & $\mathrm{L}$ & $\mathrm{H}$ & $\mathrm{H}$ \\
\hline$j_{1}$ & $\mathrm{H}$ & $\mathrm{M}$ & $\mathrm{H}$ & $\mathrm{H}$ & $\mathrm{VH}$ & $\mathrm{VH}$ & $\mathrm{H}$ & $\mathrm{H}$ & $\mathrm{H}$ & $\mathrm{M}$ & $\mathrm{H}$ & $\mathrm{VH}$ & $\mathrm{H}$ & $\mathrm{VH}$ & $\mathrm{H}$ \\
\hline$j_{2}$ & $\mathrm{H}$ & $\mathrm{H}$ & $\mathrm{M}$ & VH & $\mathrm{H}$ & $\mathrm{H}$ & VH & $\mathrm{M}$ & $\mathrm{H}$ & $\mathrm{H}$ & $\mathrm{H}$ & $\mathrm{H}$ & $\mathrm{M}$ & $\mathrm{H}$ & $\mathrm{H}$ \\
\hline$j_{3}$ & $\mathrm{M}$ & $\mathrm{L}$ & $\mathrm{M}$ & VL & VL & $\mathrm{L}$ & $\mathrm{M}$ & VL & VL & $\mathrm{M}$ & $\mathrm{M}$ & $\mathrm{L}$ & $\mathrm{L}$ & VL & $\mathrm{L}$ \\
\hline
\end{tabular}

Table 6. Decision values after standardization for each scenario and Fuzzy distance calculation table.

\begin{tabular}{|c|c|c|c|c|c|c|c|}
\hline Index & $D_{1}$ & $D_{2}$ & $D_{3}$ & $D\left(\widetilde{F}_{j}^{+}, \widetilde{A}_{1 j}\right)$ & $D\left(\widetilde{F}_{j}^{+}, \widetilde{A}_{2 j}\right)$ & $D\left(\widetilde{F}_{j}^{+}, \widetilde{A}_{3 j}\right)$ & $D\left(\widetilde{\boldsymbol{F}}_{j}^{+}, \widetilde{\boldsymbol{F}}_{j}^{-}\right)$ \\
\hline$a_{1}$ & $(0.62,0.78,0.83)$ & $(0.81,0.94,1.00)$ & $(0.72,0.86,0.91)$ & 0.17 & 0.00 & 0.09 & 0.17 \\
\hline$a_{2}$ & $(0.85,0.94,1.00)$ & $(0.71,0.85,0.92)$ & $(0.79,0.88,0.95)$ & 0.00 & 0.11 & 0.06 & 0.11 \\
\hline$b_{1}$ & $(0.75,0.80,0.86)$ & $(0.82 .0 .88,0.95)$ & $(0.87,0.92,1.00)$ & 0.13 & 0.05 & 0.00 & 0.13 \\
\hline$b_{2}$ & $(0.83,0.91,1.00)$ & $(0.65,0.79,0.91)$ & $(0.70,0.86,0.94)$ & 0.00 & 0.14 & 0.09 & 0.14 \\
\hline$b_{3}$ & $(0.68,0.82,0.92)$ & $(0.72,0.89,1.00)$ & $(0.68,0.82,0.93)$ & 0.07 & 0.00 & 0.06 & 0.07 \\
\hline$c_{1}$ & $(0.45,0.66,0.83)$ & $(0.56,0.78,0.94)$ & $(0.62,0.83,1.00)$ & 0.17 & 0.06 & 0.00 & 0.17 \\
\hline$c_{2}$ & $(0.81,0.90,1.00)$ & $(0.62,0.75,0.86)$ & $(0.68,0.82,0.89)$ & 0.00 & 0.16 & 0.11 & 0.16 \\
\hline$c_{3}$ & $(0.55,0.67,0.83)$ & $(0.68,0.75,0.87)$ & $(0.79,0.86,1.00)$ & 0.20 & 0.12 & 0.00 & 0.20 \\
\hline$c_{4}$ & $(0.72,0.85,0.95)$ & $(0.66,0.79,0.91)$ & $(0.81,0.89,1.00)$ & 0.06 & 0.12 & 0.00 & 0.12 \\
\hline$d_{1}$ & $(0.78,0.87,0.96)$ & $(0.81,0.90,1.00)$ & $(0.72 .0 .82,0.93)$ & 0.03 & 0.00 & 0.08 & 0.08 \\
\hline$d_{2}$ & $(0.39,0.49,0.72)$ & $(0.51,0.60,0.78)$ & $(0.59,0.71,1.00)$ & 0.24 & 0.15 & 0.00 & 0.24 \\
\hline$e_{1}$ & $(0.23,0.41,1.00)$ & $(0.15,0.31,0.55)$ & $(0.21,0.35,0.68)$ & 0.00 & 0.27 & 0.19 & 0.27 \\
\hline$e_{2}$ & $(0.81,0.86,0.91)$ & $(0.83,0.92,1.00)$ & $(0.80,0.82,0.90)$ & 0.15 & 0.00 & 0.08 & 0.15 \\
\hline$e_{3}$ & $(0.77,0.83,0.96)$ & $(0.81,0.88,1.00)$ & $(0.74,0.81,0.89)$ & 0.04 & 0.00 & 0.09 & 0.09 \\
\hline$f_{1}$ & $(0.71,0.83,0.93)$ & $(0.84,0.95,1.00)$ & $(0.81,0.89,0.96)$ & 0.11 & 0.00 & 0.05 & 0.11 \\
\hline$f_{2}$ & $(0.76,0.85,0.97)$ & $(0.74,0.82,0.91)$ & $(0.83,0.91,1.00)$ & 0.06 & 0.09 & 0.00 & 0.09 \\
\hline$f_{3}$ & $(0.63,0.81,1.00)$ & $(0.56,0.79,0.91)$ & $(0.55,0.78,0.83)$ & 0.00 & 0.07 & 0.11 & 0.11 \\
\hline$g_{1}$ & $(0.66,0.81,1.00)$ & $(0.61,0.73,0.90)$ & $(0.65,0.78,0.94)$ & 0.00 & 0.08 & 0.04 & 0.08 \\
\hline
\end{tabular}




\begin{tabular}{|c|c|c|c|c|c|c|c|}
\hline$g_{2}$ & $(0.28,0.53,1.00)$ & $(0.17,0.44,0.63)$ & $(0.22,0.48,0.71)$ & 0.00 & 0.23 & 0.17 & 0.23 \\
\hline$h_{1}$ & $(0.43,0.62,0.85)$ & $(0.50,0.69,0.87)$ & $(0.56,0.77,1.00)$ & 0.14 & 0.09 & 0.00 & 0.14 \\
\hline$h_{2}$ & $(0.05,0.10,0.38)$ & $(0.08,0.21,1.00)$ & $(0.06,0.16,0.59)$ & 0.36 & 0.00 & 0.24 & 0.36 \\
\hline$i_{1}$ & $(0.54,0.72,0.83)$ & $(0.62,0.77,1.00)$ & $(0.49,0.69,0.81)$ & 0.11 & 0.00 & 0.14 & 0.14 \\
\hline$i_{2}$ & $(0.60,0.82,0.97)$ & $(0.48,0.69,0.89)$ & $(0.60,0.82,1.00)$ & 0.02 & 0.12 & 0.00 & 0.12 \\
\hline$j_{1}$ & $(0.12,0.23,1.00)$ & $(0.09,0.13,0.29)$ & $(0.10,0.18,0.63)$ & 0.00 & 0.41 & 0.22 & 0.41 \\
\hline$j_{2}$ & $(0.15,0.28,0.45)$ & $(0.31,0.43,1.00)$ & $(0.26,0.39,0.63)$ & 0.34 & 0.00 & 0.22 & 0.34 \\
\hline$j_{3}$ & $(0.53,0.67,1.00)$ & $(0.41,0.49,0.61)$ & $(0.50,0.62,0.78)$ & 0.00 & 0.26 & 0.13 & 0.26 \\
\hline
\end{tabular}

\subsubsection{Optimization and ranking of investment programs}

According to equations (11) and (12), the fuzzy positive ideal solution $\tilde{F}_{j}^{+}$and the fuzzy negative ideal solution $\tilde{F}_{j}^{-}$for each index are determined. Then calculate the fuzzy distance according to equations (13) and (14). The calculation results are shown in Table 6.

According to equations (10), (11) and (14), calculate the maximum group effect $S_{i}$, the minimum regret value $R_{i}$, and the multi-criteria compromise solution ranking method synthesis index value $Q_{i}$ (where $v$ takes 0.5 ). The calculation results are shown in Table 7.

Table 7. Table of $S_{i}, R_{i}$ and $Q_{i}$ values.

\begin{tabular}{|c|c|c|c|}
\hline Index & $\boldsymbol{D}_{\mathbf{1}}$ & $\boldsymbol{D}_{\mathbf{2}}$ & $\boldsymbol{D}_{\mathbf{3}}$ \\
\hline$S_{i}$ & 0.60 & 0.54 & 0.43 \\
\hline$R_{i}$ & 0.14 & 0.10 & 0.08 \\
\hline$Q_{i}$ & 0 & 0.53 & 1 \\
\hline
\end{tabular}

Roots $S_{i}, R_{i}$, and $Q_{i}$ sort the alternatives in ascending order, and select the plan according to the decision criteria. $D_{1}$ is the scheme ranked first in ascending order of $Q_{i}$ value, satisfying $Q\left(D_{1}\right)-$ $\mathrm{Q}\left(D_{2}\right)>0.5$, but does not satisfy condition 2 , so $\mathrm{D}_{1}$ and $\mathrm{D}_{2}$ are trade-off solutions. Therefore, $\mathrm{D}_{1}$ and $\mathrm{D}_{2}$ are the final solutions determined according to the fuzzy multi-criteria compromise solution sorting method. New energy companies can invest in these two options.

\section{Conclusion}

EGS will be the key clean energy for development and utilization worldwide in the future. This paper constructs an evaluation index system for the EGS power generation investment scheme, which uses the entropy weight method and the order relationship analysis method based on group relations to calculate the comprehensive weight of the index as well. Combining the fuzzy set theory with the multi-criteria compromised sorting method, the optimal technical route for the EGS power generation investment scheme was proposed. Through this technical route, an optimal solution that takes into account the largest group effect and the smallest individual regret can be obtained, and the conflict between the ambiguity of the decision attribute and the index is properly solved.
Using this technical route, the case analysis of an EGS power plant project of a company was conducted. The results of the decision show good accuracy, which proves the validity and practicability of the framework.

\section{Acknowledgment}

The authors wish to thank anonymous reviewers for their constructive reviews and suggestions, which have greatly helped us improve this paper. This project was supported by the Fundamental Research funds for Central Universities, China University of Geosciences (Wuhan) (1810491T09) and Laboratory Research Funds, China University of Geosciences (Wuhan) (SKJ2018240).

\section{References}

1. Olasolo P, Juárez MC, Olasolo J, et al. Economic analysis of Enhanced Geothermal Systems (EGS). A review of software packages for estimating and simulating costs. Applied Thermal Engineering, 104, 647-658 (2016)

2. Wang Guiling, Zhang Wei, Liang Jiyun, et al. Evaluation of geothermal resource potential in China. Earth Journal, 38, 448-459 (2017)

3. Zhang Aiguo. The commercialization of power generation from dry hot rock still needs time. China Petrochemical News, 007 (2017)

4. Zeng Yijin. Progress and Thinking on Thermal Energy Development of Dry Hot Rock. Petroleum Drilling Technology, 2, 1-7 (2015)

5. Liu Guiying, Li Jijiang, Zhang Yang. Current Situation and Countermeasures of Geothermal Resources Exploration and Development. China Land and Resources Economics, 23, 17-20 (2010)

6. Zhuang Qingxiang. Discussion on the development potential, benefit analysis and development planning of geothermal energy resources in dry hot rock. Energy and Environment, 2, 2-3 (2017)

7. Tan $\mathrm{Xu}, \mathrm{Wu}$ Junjiang, Mao Taitian, Tan Yuejin.Multi-attribute intelligent decision-making based on triangular fuzzy number hesitant intuitionistic fuzzy sets. Systems Engineering and Electronics, 39, 829-836 (2017)

8. Jiang Wenqi. FVIKOR-based multi-criteria decision-making method for triangular fuzzy 
numbers. Control and Decision, 31, 1330-1334 (2016)

9. Tavana M, Caprio D D, Santos-Arteaga F J. An extended stochastic VIKOR model with decision maker's attitude to risk. Information Sciences, 432, 301-318 (2018)

10. Awasthi A, Govindan K, Gold S. Multi-tier sustainable global supplier selection using a fuzzy AHP-VIKOR based approach. International Journal of Production Economics, 195, 106-117 (2017)

11. Gupta P, Mehlawat MK, Grover N. Intuitionistic fuzzy multi-attribute group decision-making with an application to plant location selection based on a new extended VIKOR method. Information Sciences, s 370-371, $184-203$ (2016)

12. Hu Fang, Liu Zhihua, Li Shubiao. Research on risk assessment of public engineering projects based on entropy method and VIKOR method. Journal of Hunan University(Natural Science), 39, 83-86 (2012)

13. Wang Shuji. Study on the weight determination and evaluation method of post-composition evaluation index for large-scale irrigation area water saving reform project. Xi'an University of Technology, (2009) 